\title{
XVIII BIENAL DE SIDNEY: \\ UNA MIRADA CRÍTICA A LAS ANTÍPODAS
}

Data recepción: 2013/06/18

Carlos Tejo Veloso

Data aceptación: 2013/09/24

Universidade de Vigo

Contacto autor: carlos.tejo@uvigo.es

\section{RESUMEN}

La primera Bienal de Sídney abre sus puertas en el lejano 1973, en una flamante y ya emblemática Casa de la Ópera. Desde esa fecha hasta el pasado año este evento artístico se ha ido conformando como una de las grandes citas de prestigio a nivel internacional. Junto a São Paulo o Venecia, Sídney completa la oferta de las bienales más conocidas del planeta. El presente artículo arrancará con un breve análisis de los rasgos fundamentales que perfilaron las convocatorias más significativas de la Bienal. Complementando esta introducción continuaremos con un estudio detenido de la propuesta comisarial de la última edición y de una crítica general de las obras allí presentadas. Para concluir, centraremos nuestra atención en aquellos trabajos que por su indiscutible calidad y madurez hayan despertado nuestro interés como espectadores de la decimoctava Bienal de Sídney.

Palabras clave: Australia, arte contemporáneo, bienal.

\section{ABSTRACT}

The Sydney Biennale first took place in the distant 1973 in a brand new and iconic Opera House. From then until last year this artistic event has taken shape as one of the most prestigious international artistic events. Together with São Paulo and Venice, Sydney is one of the most famous biennales in the world. This article will start with a brief discussion on the fundamental features that outlined the most significant editions of the Biennale. Complementing this introduction we will continue with a detailed study of the latest curatorial proposal and we will give a general review of the art works that have been presented in the 2012 edition. To conclude, we will focus on those pieces that -due to their unquestionable quality and maturity- have aroused our interest as spectators of the eighteenth Sydney Biennale.

Keywords: Australia, contemporary art, biennale.

\section{El Premio de Arte Transfield como punto de partida}

El preludio de La Bienal de Sídney tiene su origen en el Premio de Arte Transfield ${ }^{1}$ que tenía como objetivo esencial promover y coleccionar arte australiano contemporáneo. Su organizador, en el año 1961, fue el emigrante italiano Franco Belgiorno-Nettis fundador de la empresa de construcción Transfield, industria que mantenía fuertes vínculos comerciales con Italia². Belgiorno-Nettis, alimentado quizás por sus propias raíces y por su continuada relación comercial, pronto demostró una profunda admiración hacia el panorama cultural de Italia y, más concre- tamente, hacia la Bienal de Venecia. Este hecho llevaría al empresario a reivindicar para Australia un evento artístico a la altura del modelo Veneciano. Junto a este deseo, el mecenas tenía otra importante aspiración: paliar el profundo aislamiento del continente provocado por la distancia de lo que por aquel entonces eran los centros de poder político y cultural. Tal y como señala Paul Greenaway ${ }^{3}$, este sentimiento de periferia, en cierto modo de crisis de identidad, se mantendrá a lo largo de los años provocando que algunos artistas llevasen a cabo un ejercicio mimético de los modelos exportados desde el centro. Sin embargo, contrariamente a la tesis 
de Greenaway encontramos otros especialistas como William Wright, director de la IV Bienal de Sídney, que ven en el aislamiento una ventaja a la hora de crear sin contaminaciones ${ }^{4}$. Flotando entre estas y otras aguas nace en 1973 la primera edición de la Bienal que, aunque modesta en su presupuesto, supo abrir Australia al mundo. Esta apertura del arte y cultura australianos vino acompañada de una intensa comunicación con determinados países de Asia y del Pacífico (China, Japón, Tailandia o Filipinas) y de un mayor protagonismo del arte aborigen que tendría una significativa presencia en las ediciones de 1979, 1982 o $1988^{5}$.

\section{Sídney apuesta por los comisariados}

La figura del comisario de arte se convierte desde la segunda edición de la Bienal en una estrategia más para dotar a Sídney de un sello distintivo frente a otras grandes bienales del momento. Tal y como nos recuerda Leon Paroissien $^{6}$, la elección de un único proyecto comisarial va a ser una de las diferencias claves frente a la referencia más potente de esos años: la Bienal de Venecia que, como sabemos, todavía hoy en día encarga a los diferentes organismos de los países representados la selección de artistas que participarán en la muestra. Anthony Bond, comisario de la Bienal de Sídney en 1992, refuerza la idea sostenida por Paroissien en el texto de introducción del catalogo de la novena edición. Sin embargo, Bond va un poco más allá al subrayar que la elección de los artistas internacionales a cargo de un comisario nombrado por el Comité Asesor de la Bienal podría llegar a ser una circunstancia desfavorable y que, a pesar de ello, Sídney pudo seguir adelante con la idea:

Normalmente se entiende una bienal como un lugar en el que las naciones despliegan sus banderas culturales. Es un espacio para la representación nacional en el cual el desarrollo de un tema unificador es totalmente impracticable. En Sídney hemos tenido la suerte suficiente como para mantener el apoyo internacional a la Bienal y al mismo tiempo conseguir que todas nuestras decisiones de selección sean competencia de nuestro propio comisario?.

Thomas G. McCullough nos ha dejado claro la importancia de esas decisiones de selección a las que aludía Anthony Bond. McCullough, director de la I/ Bienal de Sídney, fue uno de esos comisarios que ha sabido tomar valientes, significativas y ejemplarizantes determinaciones. En este sentido, la edición del año 1976 marcó una importante inflexión al ser la primera en albergar expresiones artísticas que subvirtieron con inteligencia el canon tradicional de la modernidad. Dentro de este marco, resulta lógico que la II Bienal de Sídney se la hubiesen encargado a un comisario conocido fundamentalmente por el excelente trabajo realizado en la Trienal de Escultura de Mildura ${ }^{8}$. Esta cita trianual se desarrolló entre 1961 y 1982, dando cabida a un arriesgado laboratorio para expresiones que tenían como eje la performance, la instalación o el land art. Recuperando esta línea de actuación para la Bienal, McCullough apostó por la inclusión de prácticas artísticas que cuestionaron disciplinas hegemónicas como la pintura y que se alimentaron de las aperturas producidas en la década de los sesenta en el panorama internacional ${ }^{9}$. El propio título del evento, Formas Recientes en el Arte Internaciona ${ }^{10}$, evidencia el sentido y la dirección de los proyectos allí expuestos. Tampoco debemos olvidar que, además de arriesgar con el tipo de obra seleccionada, McCullough tuvo que luchar con la presión que ejercía el deseo de continuidad del evento y con la falta de medios económicos para llevarlo a cabo ${ }^{11}$.

Nick Waterlow, director de las ediciones de los años 1979, 1986 y 1988, fue otro de los comisarios que sentó importantes precedentes en la construcción del proyecto de la Bienal. Waterlow, fallecido dramáticamente en el año 2009, era un especialista de gran relevancia en la escena artística australiana: comisario en la Art Gallery of New South Wales, también formó parte del Comité Asesor de la Bienal de Sídney desde 1994 hasta el 2006 e integró el órgano consultivo de artes plásticas del New South Wales Ministry for the Arts. La propuesta que Waterlow hizo para la III Bienal de Sídney se centraba en la compilación de trabajos europeos que no habían sido vistos en Australia y que no seguían los estándares marcados por las corrientes hegemónicas del momento. Así, llegaron a Sídney artistas como Marina Abramovic y Ulay, Daniel Buren, Mario y Marisa Merz, Marcel Broodthaers o Jürgen Klauke, entre otros. Además de disfru- 
tar de las obras, el público australiano pudo asistir a las numerosas conferencias -incluso charlas de carácter más informal- que corrían a cargo de este dinámico grupo de artistas europeos y que significaban una clara apuesta por el diálogo y la intersección de ideas entre artistas y audiencia. De ahí quizás que Dialogo Europeo ${ }^{12}$ sea el título que mejor condense el deseo de visibilizar a Australia como un lugar que desde los márgenes tiene mucho que aportar al circuito internacional del arte superando, de una vez por todas, ese sentimiento de aislamiento ya observado por Belgiorno-Nettis desde los inicios. Bajo este prisma, el comisario inglés afincado en Australia propone para Sídney un arte europeo original, ágil, lejos de las posibles contaminaciones de una producción realizada mayormente en Estados Unidos. Su propio transcurso vital, a camino entre Europa y Australia, le convierten en el interlocutor perfecto para esta aventura. El diálogo que planteaba Waterlow afectaba a ambos continentes, compartía las mismas preocupaciones y se erigía en contra de cualquier dominación. Precisamente, hablando de los peligros a los que Europa y Australia debían hacer frente, Waterlow pronuncia:

La democratización en el arte se está debilitando cuando implica estándares que se derivan de un modelo central que difunde sus logros alrededor del globo en sus propios términos. El mundo de las artes visuales es lo suficientemente pequeño (tal y como Tom Wolfe expresó en "La palabra pintada") como para permitir la dominación por parte de un solo centro hasta tal punto que deja al resto de los artistas del mundo bajo su encantamiento. ${ }^{13}$

\subsection{3-1979: la estructura principal se consolida}

A lo largo de estas tres primeras ediciones se definen un conjunto de actuaciones que marcarán la línea fundamental de las sucesivas convocatorias y que intentarán convertir a la Bienal de Sídney en un evento con personalidad propia frente a las grandes bienales del planeta. Para justificar esta idea, nos gustaría recordar los puntos clave que, bajo nuestro punto de vista, construyen y dan entidad al evento australiano: a) un fuerte deseo de internacionalizar el arte con- temporáneo australiano y -por ende- de acercar lo desconocido al resto del mundo, b) hacer de Sídney un punto de encuentro periódico para la reflexión crítica centrada principalmente en temáticas que atañen a contextos socio-culturales no hegemónicos, c) la exhibición y el análisis de prácticas periféricas -como, por ejemplo, la performance- que no destacan por su visibilidad en este tipo de eventos, d) Otorgar un mayor protagonismo al arte producido en determinados países de Asia y del Pacífico, e) la apuesta por uno o varios comisarios que establecen un hilo conductor entre las obras presentadas, f) la presencia, dentro del programa oficial de la Bienal, del arte aborigen entendido como signo identitario. En líneas generales, podemos afirmar que estas coordenadas convivirán con las diferentes personalidades que se transparentan de las distintas propuestas comisariales a lo largo de estos treinta y nueva años de historia: un mismo denominador común para una gran diversidad de tonos y matices ${ }^{14}$. Así mismo, por parte de las instituciones se pretendía fomentar entre la población una mayor valoración del arte y la cultura mediante la puesta en marcha de un evento de prestigio internacional. Esta idea también aspiraba a potenciar el capital cultural de los productos artísticos del país y, consecuentemente, aumentar la autoestima de los australianos que por aquel entonces no alcanzaba cotas demasiado altas.

Para hacer nuestro recorrido más completo no podemos olvidarnos de algunas de las voces que, bien desde la propia estructura interna de la Bienal, bien desde los medios especializados, han advertido de posibles errores o desvíos. Recordemos al ya nombrado Willian Wright, comisario en el año 1982, cuando apuntaba que se necesitaría más inversión australiana para sobrevivir ya que hasta esa fecha, los países participantes aportaban hasta el $60 \%$ de los gastos que la muestra originaba ${ }^{15}$. Bastante más duro que Wright, cabe resaltar las contundentes declaraciones del también comisario René Block. El director de la octava edición emplea un mordaz símil entre el majestuoso Edificio de la Opera y el funcionamiento interno de la Bienal. En una entrevista que publica el catalogo del propio evento, Block comenta: "(...) para mí este edifico simboliza perfectamente la situación de la 
Bienal. Fuera: magnífico e internacionalmente significativo. Dentro: catástrofe" ${ }^{16}$. En años más recientes, opiniones como la del crítico de arte australiano Jeff Gibson o conclusiones como la de James Donald ${ }^{17}$ tampoco juegan un papel demasiado favorecedor. Concretamente Gibson, en un artículo demoledor, habla de una cierta frivolidad, de un vacío en la práctica comisarial que buscaría, como objetivo principal, agradar al gran público. A modo de epílogo, Gibson hace este comentario que sintetiza de manera bastante acertada la política que, sobre todo en las últimas ediciones, parece seguir la Bienal de Sídney:

Esto refleja una tendencia general hacia el populismo en la política institucional del arte en Australia, que demasiado a menudo desemboca en exposiciones que carecen del poder económico de la industria del entretenimiento, pero que tampoco dan muestras del potencial más reflexivo o recóndito del arte. ${ }^{18}$

\section{Todas nuestras relaciones}

Todas nuestras relaciones ${ }^{19}$ es el título de la propuesta desarrollada por Catherine de Zegher y Gerald McMaster para la edición número dieciocho de la Bienal de Sídney realizada entre el 27 de junio y el 16 de septiembre de 2012. No es la primera ocasión que estos dos conocidos comisarios trabajan en equipo, basta recordar la ordenación de la colección de la Art Gallery of Ontario en los apartados dedicados a Europa y Canadá o la exposición Dibujar y Decir: Líneas de Trasnformación ${ }^{20}$, centrada en la obra de Norval Morrisseau; artista educado bajo la influencia de su abuelo, uno de los grandes guías espirituales de la comunidad Anishinaabeg radicada en Canadá. En sus trayectorias individuales ambos especialistas demuestran sobrada experiencia en el campo combinando su labor como comisarios con otras actividades como la escritura o la edición. Solamente por dar algunos ejemplos, Catherine de Zegher ha sido conocida por exposiciones con orientación de género como: Dentro de lo visible. Un Recorrido Elíptico del Arte del Siglo XX en, de y desde lo Femenino)21 (1994) $u$ otras que aglutinan trabajos centrados en la técnica del dibujo como 3 x Abstracción: nuevos métodos de dibujo por Hilma af Klint, Emma
Kunz, y Agnes Martin 22 (2005). Así mismo, Zegher ha sido elegida comisaria para el pabellón de Australia en la edición número 55 de la Bienal de Venecia. Por su parte, Gerald McMaster ha colaborado con la Art Gallery of Ontario como comisario del Canadian Art Department. Será en el mismo museo, en el año 2012, donde ha comisariado junto al especialista en arte Inuit Ingo Hessel, la exposición titulada: Inuit Actual: la Colección de Samuel y Esther Sarick ${ }^{23}$. Destacan además sus trabajos para Smithsonian's National Museum of the American Indian o el Canadian Museum of Civilization. En un gran número de proyectos llevados a cabo por McMaster se trasluce su interés por el arte primitivo que desarrollan comunidades indígenas radicadas en Canadá como por ejemplo, los Inuit.

A excepción de la Bienal inaugural y la celebrada en el año 2000 donde la selección de artistas fue realizada por un comité internacional de siete personas, la dieciocho edición de la Bienal de Sídney introduce, por vez primera, una dirección basada en el diálogo entre dos comisarios. Este punto de partida intenta enfatizar el principio de la muestra que, parafraseando a sus directores artísticos, pretende abogar por la colaboración, la comunicación y la empatía como alimentos de un organismo vivo que intentará poner freno a la distancia, la oposición, la fractura y la incomunicación que abundan en occidente desde la modernidad ${ }^{24}$. Siguiendo el sentido general propuesto por Zegher y McMaster, este organismo mutante produce una reflexión analítica que defiende las relaciones entre los seres humanos como método para crecer conjuntamente, explora la creación de una estructura dinámica donde nuestras energías confluyen en la búsqueda del conocimiento y lucha en contra de una creciente individualidad. Detengámonos en las palabras que Catherine de Zegher ha escrito para el catalogo y que mejor condensan estas ideas:

La premisa de Todas nuestras relaciones, tanto con los artistas como con la audiencia, permite no sólo la conexión de lo local con lo global y la yuxtaposición de diversas culturas, sino también la preferencia por un modelo de interrelación y confianza mutua. La yuxtaposición, en este modelo, no busca la confrontación y la eliminación, 
sino que genera conversación y negociación, haciendo posible el entendimiento. ${ }^{25}$

Todos estos conceptos claves que Zegher y McMaster seguirán ampliando en el transcurrir de sus respectivos textos (conexión, yuxtaposición, interrelación, conversación, negociación o entendimiento) construyen la compleja red teórica que sustenta el corpus del comisariado. Sin embargo, a pesar de hallarnos frente a una hipótesis muy bien argumentada, las obras seleccionadas para la Bienal alimentan lecturas divergentes y traslucen -a nuestro parecer- un itinerario confuso donde casi todas las rutas son posibles. La reflexión tras la contemplación se expande tantísimo que el espectador, a medida que avanza por las diferentes localizaciones, pierde ese necesario hilo argumental que unifica y justifica las obras expuestas. Y no nos basta la reflexión de McMaster cuando define los trabajos que integran la Bienal como una serie de tramas que se relacionan, traducen y relatan a sí mismas en un bucle $\sin$ fin $^{26}$. Así mismo, esa conexión, esa coherencia, esa búsqueda de estructuras que puedan superar la fragmentación, ese apoyarse en la necesaria conversación entre las obras, en definitiva, ese dialogo que nos relaciona y lo relaciona todo por el que también aboga Catherine de Zegher ${ }^{27}$, parece que va perdiendo, paulatinamente, cualidades para ser legible. El espectador se ve enfrentado a un heterogéneo crisol de subjetividades: zonas de contacto extremadamente frágiles que no justifican la propuesta comisarial. En este sentido (que no en la indudable calidad de algunas de las obras expuestas) Todas nuestras relaciones destila cierta indefinición y transparenta una escurridiza disparidad que esquiva la oportunidad que le podía brindar una temática muy bien construida a nivel teórico. Somos conscientes que la práctica artística contemporánea se caracteriza por elevadas tasas de subjetividad y que, a su vez, lo subjetivo se abre a múltiples interpretaciones. Aún así, consideramos que dentro de la práctica comisarial deberían ponerse en juego estrategias que puedan definir con mayor precisión el vórtice sobre el que van a girar las obras presentadas. $Y$ no queremos reivindicar con ello el papel del clásico comisario que, casi asumiendo una práctica museológica, ordena, clasifica y acota. Lejos de esta idea, concordamos con Daniel Birnbaum cuando, parafraseando a Harald Szeemann, nos recuerda que el arte de planificar una exposición debe evolucionar y abrirse paso hacia propuestas que pudieran ser entendidas como "poemas en el espacio"28. Como admiradores de la labor desarrollada por Szeemann, respetamos y agradecemos ese ejercicio poético siempre excelentemente construido. Sin embargo, en la XVIII Bienal de Sídney echamos de menos un centro alrededor del cual las obras pudiesen describir órbitas más o menos cercanas. Así, no hemos visto claro ese necesario recorrido orbital y nuestra nave se ha perdido una, otra vez y otra también.

\subsection{En el Finito Planeta Azul}

Los espacios expositivos de la Bienal se reparten, como viene siendo costumbre, entre la Art Gallery of New South Wales, Museum of Contemporary Art, Pier 2/3 y Cockatoo Island. Aunque la intención general del comisariado prevalece en todos estos espacios, podemos afirmar que cada lugar dibuja, con cierta autonomía, otros núcleos temáticos que abren sugerentes vías de diálogo e interpretación. Así, los diferentes lugares se definen con un subtítulo que podría arrojar alguna pista sobre la idea que aglutina las obras en exposición. La Art Gallery of New South Wales es una de las localizaciones emblemáticas de la historia de la Bienal y en esta ocasión reúne a un grupo de 26 artistas bajo el epígrafe titulado: En el Finito Planeta Azul29. Intentando relacionar la base conceptual propuesta por Zegher y McMaster, intuimos que las obras de este apartado plantean una reflexión amplia sobre nuestra tensa dependencia con el planeta donde peligros de toda índole nos hacen cambiar, día a día, nuestras perspectivas. Parece que ya nada puede ser estable. Dentro de esta inestabilidad hemos descubierto propuestas que, utilizando diferentes medios y procesos, han capturado nuestro interés. Concretamente, nos referimos a los proyectos del colectivo Postcommodity ${ }^{30}$, Judy Watson, Jin Shi y Nipan Oranniwesna, el excelente video de Guido van der Werve o la documentación de un especial viaje llevado a cabo por Bouchra Khalili.

Tras la observación de todos estos trabajos, la obra titulada Número ocho, todo estará bien ${ }^{31}$ 


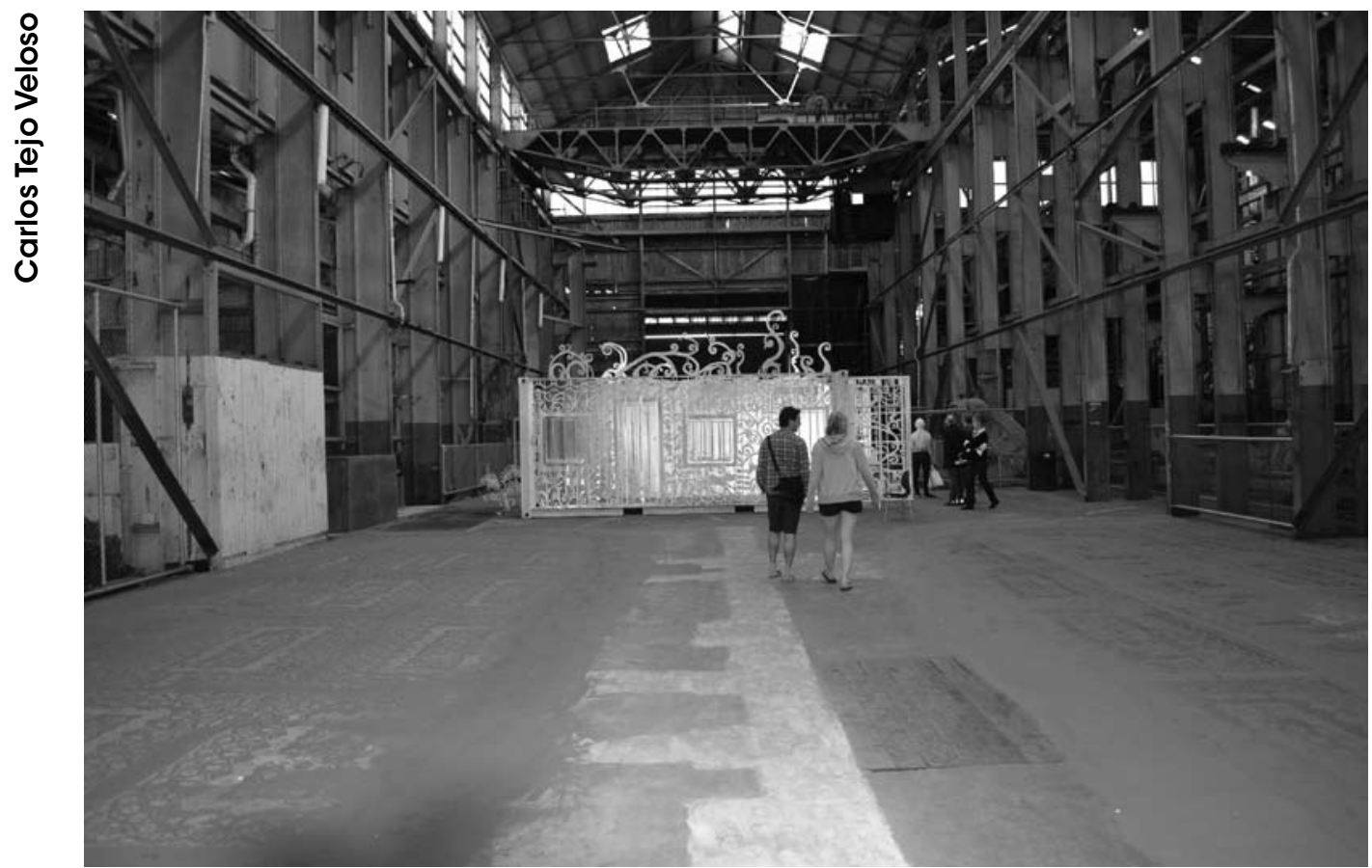

Cal Lane, Césped Domesticado, 2012, XVIII Bienal de Sídney, Edificio 140 de Cockatoo Island. Fotografía de Carlos Tejo

(2007) de Guido van der Werve (Papendrecht, Holanda, 1977) ha supuesto una agradable sorpresa. "Directo e hipnótico" son dos palabras muy bien escogidas por Zegher para resumir este imponente video que nos atrapa desde el primer minuto ${ }^{32}$. En una pantalla de grandes dimensiones podemos ver como un hombre, perdido ante la inmensidad de un mar congelado, camina tranquilo sin percatarse de la constante amenaza de un enorme rompe-hielos que parece querer devorar cada uno de sus pasos. En este documento de la performance realizada en las inmediaciones del Golfo de Botnia en la costa de Finlandia, el artista holandés nos sobrecoge con una poética imagen que bien podría resumir la incertidumbre del mañana en nuestra frágil y viciada sociedad contemporánea.

\subsection{Composición Posible}

Composición Posible ${ }^{33}$ es el título que unifica a los 25 artistas que podemos ver en El Museum of Contemporary Art Australia, institución con un gran potencial de espectadores situada en una de las zonas más animadas de la ciudad.
Para comprender mejor el sentido del término "Composición" y su relación con las obras seleccionadas, Catherine de Zegher nos remite al filósofo y antropólogo francés Bruno Latour quien, en un brillante texto incluido también en el catalogo de la Bienal, analiza la etimología de la palabra y sus derivaciones:

Aunque la palabra "composición" es un poco larga y tortuosa, lo que es interesante es que subraya que las cosas tienen que ser unidas (del latin componere) al tiempo que conservan su heterogeneidad. También está conectada con compostura (...) no está muy lejos de "compromiso" y "comprometido", conservando un cierto sabor diplomático y prudente. ${ }^{34}$

Esta entidad heterogénea pero a la vez unitaria sugerida por Latour, nos remite nuevamente al deseo, manifestado por los comisarios de la Bienal, de conseguir un crecimiento (orgánico) que respete la disparidad, sepa relacionarse con el todo y conforme un conjunto equilibrado entre sus partes. En esta declaración, el filósofo francés también vincula la palabra "composición" con "compromiso" y "comprometido": 
un juego de correspondencias donde intervienen vectores que, desde una visión relativista, podrían ceder en el dialogo apostando por una estructura revisable y diversa. Bajo estas ideas, los artistas invitados a esta sección plantean un assemblage a partir de las piezas de un puzle roto, sustituyendo la separación y la fragmentación por una re-composición que -a través de la deconstrucción- descubre una nueva estructura con otra forma y otro significado. Uno de los trabajos que, según nuestro punto de vista, mejor ejemplifica el espíritu de Composición Posible es el titulado El Proyecto Reparador 35 (2009) del artista Lee Mingwei (1964, Taipei, Taiwán). Además de la obra del artista taiwanés, nos ha interesado especialmente la sugerente poética de Gabriella Mangano y Silvana Mangano (Stanthorpe, Australia, 1972). El video de estas hermanas gemelas plantea un ejercicio lúdico a partir de conceptos como simetría, múltiple, repetición, cuerpo, o musicalidad. Entre lo lejano y lo cercano ${ }^{36}$ (2008-2009) toma forma de video-instalación con una clara preferencia por lo minimal realizando una suerte de performance ante la cámara que investiga las posibilidades de relación entre el paisaje, el cuerpo y el objeto. Incluyendo estrategias de la danza, este trabajo nos enseña a dialogar sin palabras a través de breves y rítmicas acciones que destilan compenetración, reciprocidad y entendimiento.

\subsection{Tanto por arriba como por abajo.}

Pier 2/3 es uno de los varios embarcaderos que existen en el centro de la ciudad de Sídney. Como apunta Catherine de Zegher, es uno de los últimos muelles que todavía no se ha integrado plenamente al proyecto Walsh Bay ${ }^{37}$. Este proyecto, conocido por el informe Walsh Bay Arts Precinct Vision, ha diseñado un completo plan de actuación que selecciona a una serie de instituciones ligadas a la cultura para dinamizar esta zona de la ciudad y mostrar sus producciones de manera regular ${ }^{38}$. La Bienal de Sídney, desde el año 1986, ha usado este espacio como otra de sus sedes durante siete ediciones. El título elegido para la sección que la Bienal del año 2012 mostró en el Pier 2/3 fue: Tanto por arriba como por abajo ${ }^{39}$. En esta sección que reflexionaba sobre la unión de opuestos que se complementan (cielo y tierra, público y privado, etc) solamen- te se han expuesto los trabajos de tres artistas que se centraron en la instalación. Pier $2 / 3$ se concibe, a su vez, como un punto de tránsito y conexión desde la tierra firme al islote conocido por el nombre de Cockatoo Island; un lugar donde hemos podido encontrar un extenso número de obras con un destacado interés.

\subsection{Historias, sentidos y esferas}

Historias, sentidos y esferas ${ }^{40}$ es la sección más extensa de la Bienal donde se exhiben los trabajos de 49 artistas. Todo este conjunto de proyectos se localiza en una amplia zona industrial abandonada conocida como Cockatoo island: un bello islote en medio de la espectacular Bahía de Sídney. Una vez allí, rápidamente comprobamos que estamos ante un lugar cargado de energía pero quizás poco neutro como lugar de exhibición. En este sentido, las distintas naves de Cockatoo Island funcionan de manera bipolar: por un lado, albergan piezas que dialogan fantásticamente con el espacio (Daan Roosegaarde, Fujiko Nakaya o Cal Lane ${ }^{41}$ ) y por el otro, nos encontramos con ubicaciones en los que el propio espacio es un claro factor en contra (Li Hongbo o Peter Robinson). Aun así, salvando algunos posibles errores, la elección de Cockatoo Island como otra de las sedes de la Bienal nos ha parecido un gran acierto.

Historias, sentidos y esferas se divide en dos grandes zonas: la isla inferior y la isla superior ${ }^{42}$ que, a su vez se subdivide en dos nuevas localizaciones. Este gran conjunto expositivo profundiza en algunas de las ideas centrales de la propuesta de Zegher y McMaster encontrando en el agua, el viento y la tierra grandes centros temáticos que vuelven a hablar de correspondencia, dialogo e interrelación. Será en Cockatoo Island donde descubramos un mayor número de proyectos en progreso e interactivos. La performance, como por ejemplo el trabajo de la artista japonesa Sachiko Abe (Nara, Japón, 1975), Ewa Partum (Grodzisk Mazowiecki, Polonia, 1945) o Khadija Baker (Amuda, Siria, 1973) ha tenido una presencia especial en la isla. También aquí hemos podido ver a la única artista española que participa en la Bienal, Cristina Iglesias (San Sebastián, 1956) que presenta sus enigmáticas piezas tituladas Vers la terre (2011), 


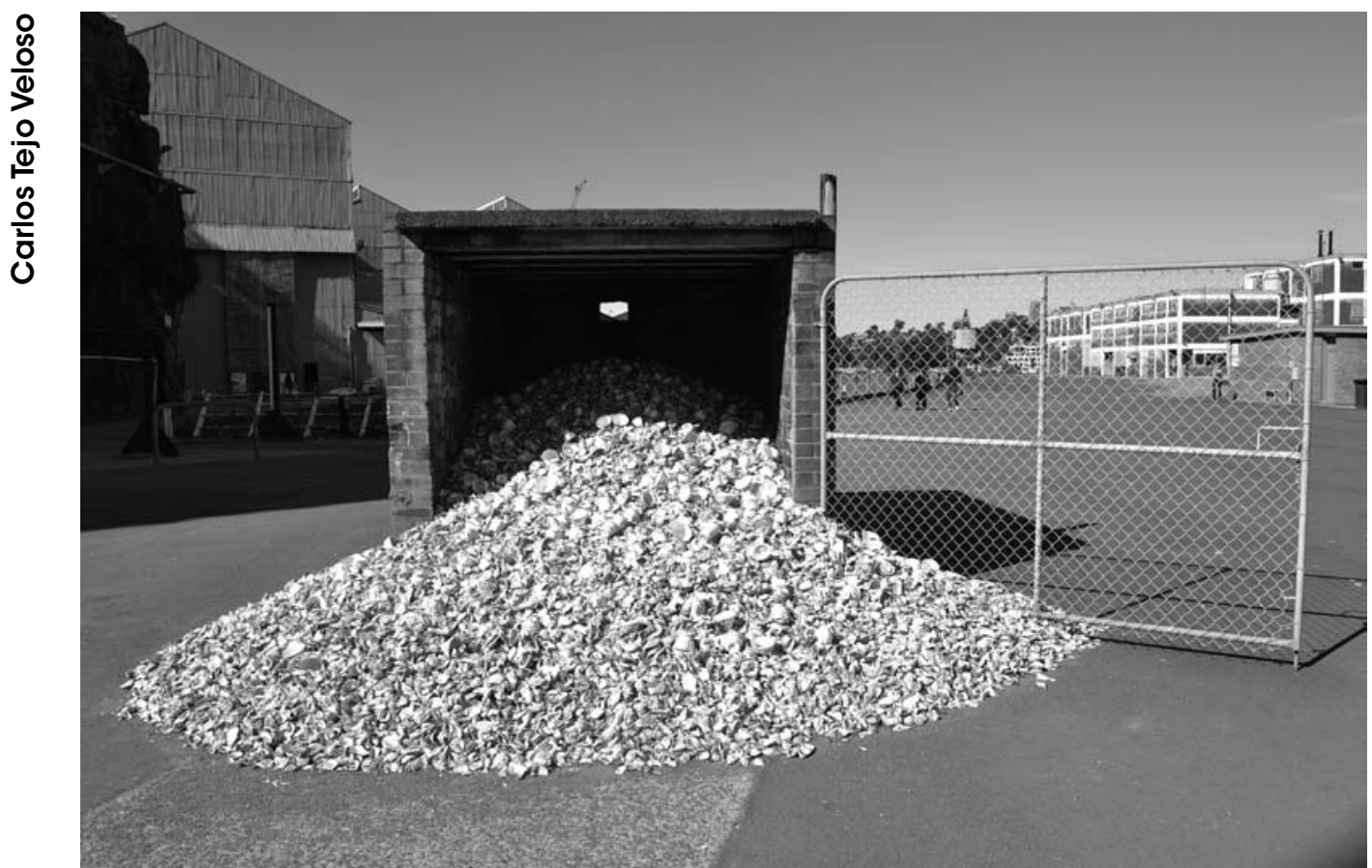

Jonathan Jones, Sin título (ostras y tazas de té), 2012, XVIII Bienal de Sídney, localización n 18 de la Isla Inferior, Cockatoo Island. Fotografía de Carlos Tejo

Pozo / (2011) y Pozo /I (2011). Junto a Cristina Iglesias nos gustaría destacar el particular teatro de marionetas de Eva Kotátková (Praga, República Checa, 1982), el irónico e inquietante Museo de Órganos Copulatorios que María Fernández Cardoso (Bogotá, Colombia, 1963) realiza en colaboración con el artista australiano Ross Rudesch Harley (Sídney, Australia, 1961), la poética niebla de Fujiko Nakaya (Sapporo, Japón, 1933), la cómica catástrofe de Lyndal Jones (Sídney, Australia, 1949) o la punzante metáfora de Jonathan Jones (Sídney, Australia, 1978). Dentro de estos excelentes proyectos, han sido los trabajos presentados por Lyndal Jones (Ensayando la catástrofe: El Arca en Síd$n e y^{43}, 2012$ ) y Jonathan Jones (Sin título lostras y tazas de tét4], 2012) los que más han despertado nuestro interés. Jonathan Jones ha trabajado únicamente con dos elementos de una gran carga simbólica: un gran montículo de conchas que algunos antropólogos ${ }^{45}$ relacionan con una práctica ancestral llevada a cabo en zonas costeras por comunidades aborígenes y numerosas tazas de té de la más fina porcelana. Estos dos materiales aparecen caóticamente mezclados, invitándonos a reflexionar sobre la cruel colonización británica en el continente pero también sobre la hibridación y mestizaje que se produce en la mayoría de los procesos de colonización. El joven artista australiano es conocido por su interés hacia la cultura aborigen, su predilección por los site-specific y el uso de materiales del ámbito cotidiano que exploren la relación entre los términos comunitario-individual, público-privado o histórico-contemporáneo.

\section{Apuntes finales}

Entre las 40 nacionalidades representadas en la XVIII Bienal de Sídney, Australia es el país con el mayor número artistas y/o colectivos (12). Le sigue, en segundo lugar, China (8) y en el tercer puesto nos encontramos con Tailandia (7). Estos datos nos confirman que el evento mantiene, como hemos señalado al principio del artículo, un marcado interés por el arte producido en Australia y en la región de Asia-Pacífico. De 


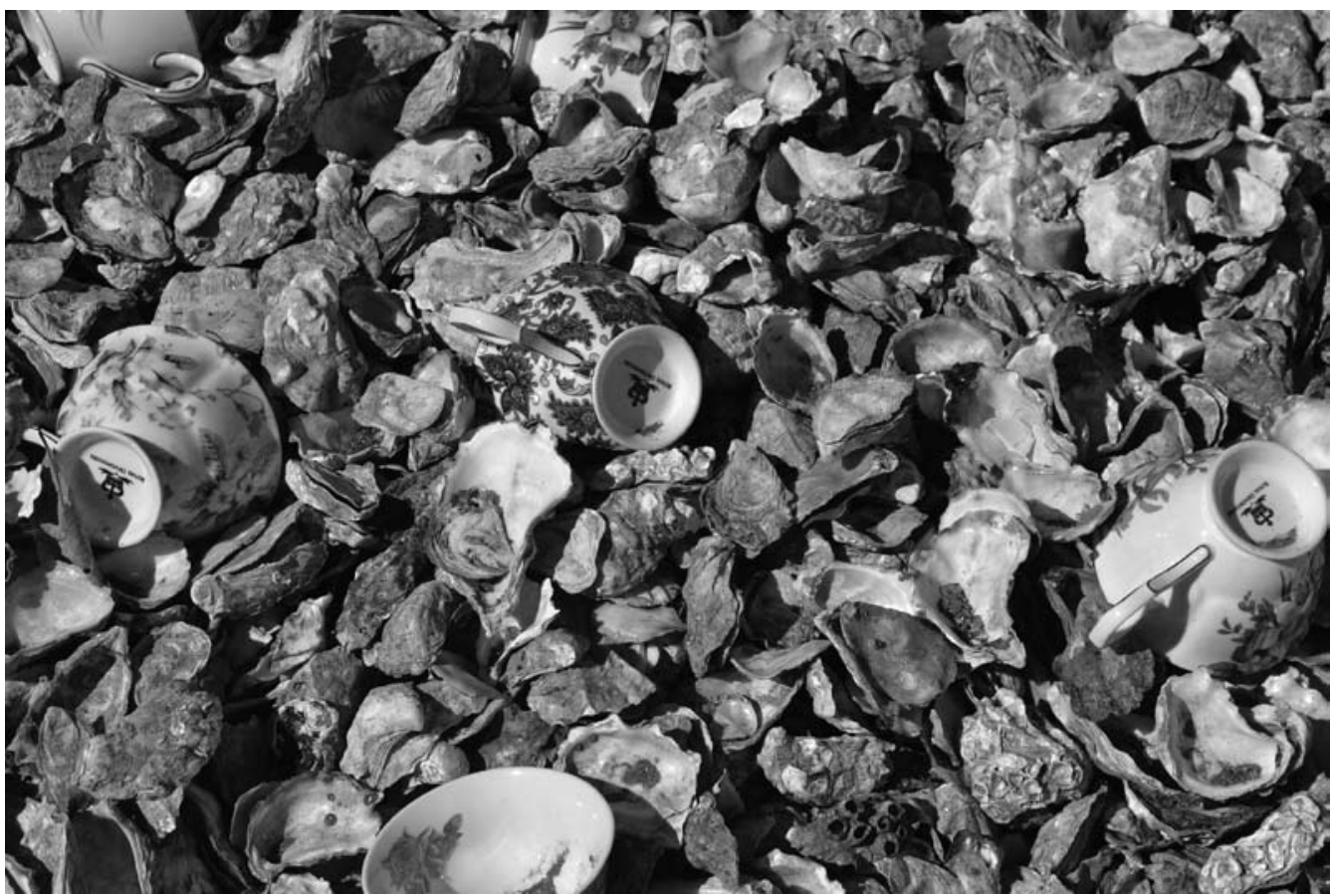

Jonathan Jones, Sin título (ostras y tazas de té), (detalle), 2012, XVIII Bienal de Sídney, localización n 18 de la Isla Inferior, Cockatoo Island. Fotografía de Carlos Tejo

los artistas australianos representados autores como Dorothy Napangardi, Makinti Napanangka, Euraba Artists and Papermakers ${ }^{46}$ o Alick Tipoti pertenecen a diferentes etnias de la cultura aborigen. Así mismo, también encontramos representación de lugares poco habituales en estas muestras como Líbano, Kazajistán o Tanzania. Ello demuestra que, tanto el arte aborigen como las prácticas artísticas producidas desde la periferia, siguen siendo puntos de interés para la Bienal. Junto a las diferentes exposiciones, se han desarrollado un extensísimo calendario de actividades complementarias. Desde el 27 de junio al 16 de septiembre el público pudo asistir ininterrumpidamente a un verdadero frenesí de conferencias, visitas guiadas por artistas, charlas informales de los artistas participantes, proyecciones, talleres prácticos, seminarios teóricos, o tours de carácter especial. Por otro lado, la performance ha tenido un lugar destacado dentro de la programación y, desde la inauguración has- ta el cierre, se han podido ver diferentes aproximaciones a esta disciplina de la mano de artistas como Cal Lane, Sachiko Abe o Ewa Partum. En líneas generales, estos hechos nos permiten afirmar que la Bienal de Sídney mantiene viva la línea de actuación propuesta por comisarios tan alejados en el tiempo como McCullough o Nick Waterlow. Pese a esta observación, somos plenamente conscientes que hoy en día existen otras bienales sensibles a este tipo de preocupaciones en parte porque -como nos recuerda Daniel Birnbaun- el modelo clásico de bienal hace ya algún tiempo que está en crisis ${ }^{47}$. Frente a una mayor competencia y asumiendo nuevas audiencias y contextos, Sídney ya prepara su XIX edición que se desarrollará del 21 de marzo al 9 de junio de 2014. Para ello, la comisaria Juliana Engberg seleccionará proyectos bajo el sugerente título Imaginas lo que deseas ${ }^{48}$. Sin duda una muy buena oportunidad para regresar a la Bienal de nuestras antípodas. 


\section{NOTAS}

1 Traducido del título original en inglés: "Transfield Art Prize". (Traducción del autor).

2 Si se desea ampliar información consultar: http://www.transfield.com. au/arts/arts.htm [Consulta: 11/12/2012]

${ }^{3}$ Cf. P. Greenaway, "Australia en ARCO'02" en WVAA, ARCO'02. Feria Internacional de Arte Contemporáneo, Madrid: IFEMA, 2002, pp. 486-487.

${ }^{4}$ Cf. W. Wright, "Director's Statement" en Vision in disbelief. The fourth Biennale of Sydney, 7th April-23rd May 1982, Sídney: Biennale of Sydney, 1982, p. 9.

${ }^{5}$ La visibilización del arte aborigen produjo cierta polémica dentro y fuera del contexto de la muestra. Para muchos sectores críticos -entre los que se encontraban grupos de comunidades aborígenes- este protagonismo no fue más que un cínico lavado de cara de las autoridades australianas frente al exterminio indiscriminado y la segregación que tuvo que sufrir, y todavía sufre, el pueblo aborigen.

6 Cf. L. Paroissien, "A partisan view of three decades", Art \& Australia, Spring, vol. 41, n 1, 2003, pp. 60-69.

${ }^{7} \mathrm{~A}$. Bond, "Notes on the Catalogue and Exhibition" en The boundary rider: 9th Biennale of Sydney:15 December 1992-14 March 1993, Sídney: Biennale of Sydney, 1992, p. 14

8 Traducido del título original en inglés: "Mildura Sculpture Triennial". (Traducción del autor)

${ }^{9}$ Esta apuesta por un arte renovado se transparentaba en algunas de las obras presentadas en la bienal como Fog Sculpture de Fujiko Nakaya, Event for Stretched Skin de Sterlac, Horizontal Line de Tsuneo Nakai o Eurasia de Joseph Beuys.

10 Traducido del título original en inglés: "Recent International Forms In Art". (Traducción del autor)

${ }^{11}$ Como comentaremos más adelante, esta precariedad económica se mantiene en el tiempo. William Wright, comisario de la IV Bienal, denuncia abiertamente la poca inversión de las instituciones australianas en el presupuesto general de la Bienal.
12 Traducido del título original en inglés: "European Dialogue". (Traducción del autor)

${ }^{13} \mathrm{~N}$. Waterlow, "European Dialogue" en European dialogue: The third Biennale of Sydney at The Art Gallery of New South Wales, The Australian Center for Photography and other venues: 14 April-27 May 1979, Sídney: Biennale of Sydney, 1979, sin paginar, (Traducción del autor).

14 Entre la extensa lista de comisarios y comisarias recordemos al ya nombrado Thomas G. McCullough ( $2^{a}$ Bienal, 1976), Nick Waterlow (3 $3^{\text {a }}$ Bie-

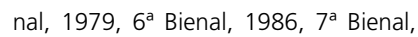
1988), René Block (8 ${ }^{a}$ Bienal, 1990), Isabel Carlos (14 $4^{a}$ Bienal, 2004), David

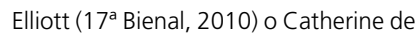
Zegher y Gerald McMaster (18 Bienal, 2012), entre otros.

15 Cf. W. Wright, "Vision in disbelief", 4th Biennale of Sydney, 1982, [Consulta: 12/11/2012]. http://www. biennaleofsydney.com.au/about/history/1982

${ }^{16} \mathrm{R}$. Block, "Art is beautiful... but it makes a lot of work" en VVAA. The readymade boomerang. Certain relations in 20th century art, Sídney: Biennale of Sydney, 1990, p. 10.(Traducción del autor).

${ }^{17} \mathrm{Cf}$. J. Donald, "The beauty of Distance: Global Art in the Contex of the 17th Sydney Biennale", YISHU: Journal of Contemporary Chinese Art, Vol. 9, $n^{\circ}$ 6, November-December, 2010, pp. 94-101

$18 \mathrm{~J}$. Gibson, "Biennale of Sydney 2002. Various Venues", ArtForum International XLJ, n³, November, 2002, p. 198. (Traducción del autor).

${ }_{19}$ Traducido del título original en inglés: "All our relations". (Traducción del autor)

${ }^{20}$ Traducido del título original en inglés: Draw \& Tell: "Lines of Transformation". (Traducción del autor)

21 Traducido del título original en inglés: "Inside the Visible. An Elliptical Traverse of Twentieth-Century Art in, of, and from the Feminine (1994)". (Traducción del autor).

22 Traducido del título original en inglés: "3 x Abstraction: new methods of drawing by Hilma af Klint, Emma
Kunz, and Agnes Martin". (Traducción del autor).

${ }^{23}$ Traducido del título original en inglés: "Inuit Modern: Art from the Samuel and Esther Sarick Collection". (Traducción del autor)

${ }^{24} \mathrm{Cf}$. C. de Zegher, G. McMaster, "All our relations" en 18 th Biennale of Sydney: all our relations, Sídney: Biennale of Sydney, 2012, p. 49.

${ }^{25}$ C. de Zegher, "Arc, are, ark, arm, art... act!" en 18 th Biennale of Sydney: all our relations, ed. cit., p. 114

${ }^{26}$ Cf. G. McMaster, "Ntotemuck: commonalities among great differences" en 18 th Biennale of Sydney: all our relations, ed. cit., pp. 307-333

27 Cf. C. de Zegher, ibidem. pp. 99-143

${ }^{28}$ D. Birnbaum, "La arqueología de lo que nos espera" en Hans Ulrich Obrist. Breve historia del comisariado, Exit Publicaciones, Madrid, 2010, p. 260

29 Traducido del título original en inglés: "In Finite Blue Planet". (Traducción del autor)

${ }^{30}$ El colectivo Postcommodity lo forman: Raven Chacon, Cristóbal Martínez, Kade L. Twist, Steven Yazzie y Nathan Young.

${ }^{31}$ El título original combina dos idiomas: el alemán y el inglés: "Nummer acht, everything is going to be alright". La traducción de ambos idiomas es: Número ocho, todo estará bien. (Traducción del autor)

${ }^{32}$ Cf. C. de Zegher, ibidem., p. 106

${ }^{33}$ Traducido del título original en inglés: "Possible Composition". (Tradución del autor)

34 B. Latour, "An Attempt at a "Compositionist Manifesto"" en 18 th Biennale of Sydney: all our relations, ed. cit., p. 67

35 Traducido del título original en inglés: "The Mending Project". (Traducción del autor). Las personas que visitaban la obra de Mingwei llevaban una prenda de ropa que necesitaba ser cosida en alguna de sus partes. Será el espectador el que también elija el hilo y será el propio artista quien, ante ese espectador, cosa pacientemente la prenda deteriorada. 
${ }^{36}$ Traducido del título original en inglés: "Between near and far". (Traducción del autor)

${ }^{37}$ Cf. C. de Zegher, "Pier 2/3. As above, as below" en 18 th Biennale of Sydney: all our relations, op. cit. pp. 120-121

38 Las instituciones a las que hacemos referencia son: Australian Chamber Orchestra, Australian Theatre for Young People, Bangarra Dance Theatre, Bell Shakespear y el Sydney Writers' Festival.Para una mayor información sobre el informe consultar: Walsh Bay Arts Precinct Vision [Consulta: 03/04/2013]. http://www.arts.nsw. gov.au/wp-content/uploads/2010/10/
Walsh-Bay-Vision-Report-Final-23-Jan2012-reduced-size1.pdf

${ }^{39}$ Traducido del título original en inglés: "As above, as below". (Traducción del autor).

${ }^{40}$ Traducido del título original en inglés: "Stories, Senses and Spheres". (Traducción del autor)

${ }^{41}$ ver Fig. 1

${ }^{42}$ Traducido del título original en inglés: "lower island" y "upper island" respectivamente. (Traducción del autor)

${ }^{43}$ Traducido del título original en inglés: "Rehearsing Catastrophe: The Ark in Sydney". (Traducción del autor)
44 Traducido del título original en inglés: "untitled. (oysters and tea cups)". (Traducción del autor).

${ }^{45}$ Cf. G.N. Bailey, "Shell Mounds, Shell Middens, and Raised Beaches in the Cape York Peninsula", TAJA (The Australian Journal of Anthropology), Vol. 11, $n^{\circ} 2$, December, 1977, pp. 132-143

${ }^{46}$ Colectivo de once artistas que viven y trabajan en Toomelah y Boggabilla (Australia)

47 Cf. D. Birnbaum, op. cit. pp. $257-261$

48 Traducido del título original en inglés: "You imagine what you desire". (Traducción del autor). 